\title{
Isolated congenital digital clubbing
}

\author{
INSERM
}

\section{Source}

INSERM. (1999). Orphanet: an online rare disease and orphan drug data base. Isolated congenital digital clubbing. ORPHA:217059

Isolated congenital digital clubbing is a rare genodermatosis disorder characterized by enlargement of the terminal segments of fingers and toes with thickened nails without any other abnormality. 